\title{
A review of ocular genetics and inherited eye diseases
}

\section{SD Mathebula}

Department of Optometry, University of Limpopo, Private Bag x1106, Sovenga, 0727 South Africa

<solani.mathebula@ul.ac.za>

Received 23 April 2012; revised version accepted 2 November 2012

\begin{abstract}
During the past twenty years, there has been an exponential increase in the knowledge and understanding of ocular genetic diseases and syndromes. The number of human eye diseases that have a known genetic or hereditary component continues to increase. In addition, genetic diseases are the most common cause of blindness in infants and children in developed countries. Optometrists are likely to encounter patients with inherited eye disorders. They may be the first clinician the patient consults. Inherited eye diseases may be isolated (only affecting the eye) or part of a complicated syndrome. Both isolated eye diseases and genetic syndromes can have identifiable gene mutation known to cause the disease.
\end{abstract}

Knowledge of the clinical and molecular features of ocular genetics and inherited eye diseases is important for appropriate diagnosis and patient management. This article reviews the current information on ocular genetics and inherited eye diseases. The ocular conditions described in the review have significant visual impairment and blindness consequences. Therefore, optometrists (as the mostly likely first line of consultation) should be able to diagnose the condition appropriately first before they could make any management, care or referral plan. Visual aids are, of course, one of the management options for such patients with visual impairment. (S Afr Optom 2012 71(4) 178-189)

Key words: Ocular genetics, gene, genome, mutation, Mendelian genetics.

\section{Introduction}

The interest in ocular genetics by ophthalmologists who described the patterns of inheritance of familiar eye diseases contributed much to the human discovery of ocular genetics. The pace of genes (units of heredity) discovery has increased a lot and we now have the Human Genome Database ${ }^{1-4}$. Of the approximately 4000 genetic diseases and syndromes known to affect humans, at least one-third involve the eye $^{3-6}$. Over the last two decades, there has been an exponential increase in our knowledge of genetic eye diseases and syndromes. The purpose of this paper is to provide a review of the current understanding of ocular genetics. This may be useful to clinicians and researchers in their ability to provide accurate genetic diagnosis and appropriate counselling to patients and their families.

\section{Basics of genetics}

Genetics is the study of hereditary and the variation of inherited characteristics ${ }^{6}$. It is a matter of general observation that the cubs of a lion resemble the lion and pups of a dog resemble the dog not only in shape but also in habits, strength and func- 
tional abilities. Surely, there is something common between the parents and their offspring which is responsible for such resemblance. Many speculations were made but none turned out to be correct unless mode of hereditary in sexually reproducing animals was explained. It was Mendel who gave the concept of "factor" being transmitted from parents to offspring $^{3}$. These factors are known as genes.

A cell is a microscopic unit surrounded by a cell membrane in animals and a true cell wall in plants ${ }^{2}$. The inner material, cytoplasm, consists of a nucleus in the centre and many microscopic organelles such as mitochondria, Golgi bodies, centrosome, endoplasmic reticulum, et cetera, which perform specialized functions in the cell. The nucleus contains a sap - the nucleoplasm and thread like bodies called chromosomes. The chromosomes are the structural unit of inheritance and carry many genes within them which are the functional unit of a character or trait ${ }^{3}$. The position where a gene rests on the chromosome is termed a locus. Each species has a specific number of chromosomes ${ }^{4}$.

In human beings, all the genetic information or genome is split between 23 pairs of chromosomes ${ }^{7-9}$. Therefore, the human genome is distributed among 46 chromosomes. One of the 23 pairs is the sex chromosome. The other 22 pairs of chromosomes are found in both males and females, and are called autosomes. One chromosome in each of the 22 homologous pairs is derived from the mother and one from the father. The only exception is the sex chromosomes, which come in two forms: $\mathrm{X}$ or $\mathrm{Y}$. The sex chromosomes present determine the sex of the individual. The presence of two $\mathrm{X}$ chromosomes gives birth to a female, homozygous. On the other hand, the XY composition symbolizes the male, heterozygous chromosomes. A condition of YY chromosomes does not exist. Males have only one $\mathrm{X}$ and therefore, only one set of alleles for all genes on $\mathrm{X}$, while females have paired alleles on their sex chromosomes. An allele is an alternate form of a gene found at the same locus on homologous chromosome ${ }^{8}$.

The human genome ${ }^{9}$ is made up of deoxyribonucleic acid (DNA), which consists of a long sequence of nucleotide bases of four types: adenine (A), cytosine $(C)$, guanine $(G)$ and thymine $(T)$. In the nucleus of a cell, the DNA is double stranded. Strong covalent bonds bind bases together along a single strand, and weaker hydrogen bonds pair $\mathrm{A}$ with $\mathrm{T}$ and $\mathrm{C}$ with $\mathrm{G}$ between the two strands. Some sections of bases act as assembly instructions for proteins ${ }^{9}$. All proteins are made from amino acids and therefore, DNA acts as a set of instructions for the order of amino acids from which the protein is made. Specific triplets of bases (codons) correspond with specific amino acids. Because there are four bases (A, $\mathrm{C}, \mathrm{G}$ and $\mathrm{T}$ ), 24 triplet combinations are possible. Since there are only 20 amino acids, there is much redundancy in the genetic code. Each set of instructions along the DNA strand is a gene, and so genes are expressed as to form proteins ${ }^{10,11}$. The final result of a genetic expression is known as genotype. Double-stranded DNA is replicated by breakage of the two strands and formation of a new complementary strand for each, resulting in two identical copies of the original ${ }^{10,11}$. A single strand of DNA can also act as a template for a complementary strand ribonucleic acid (RNA). This transcription RNA is similar to DNA, but T is replaced by uracil (U) ${ }^{9}$.

Cell division and accompanying replication and partitioning of DNA that leads to the formation of sperm and ova is meiosis ${ }^{8,9}$. Meiosis is the process by which one chromosome of a homologous pair is incorporated into gamete (sperm or ova $)^{8,9}$. During meiosis one partner of each pair of chromosomes passes into daughter cells with the result that each daughter cell has half the number of chromosomes of the parent cell. Each gamete receives at random one member of each homologous chromosomal pair ${ }^{8,9}$.

In addition to the 46 ( 44 autosomes and two sex) chromosomes that make up a human nuclear DNA (nDNA), there is a small extrachromosomal double strand circle of DNA that is essential for life - the mitochondrial genome (mtDNA) ${ }^{12-17}$. The mtDNA consist of heavy and light strands and encodes 13 polypeptides, two ribosomal RNAs and 22 transfer RNAs $^{12-17}$. The mitochondrial genome plays an important role in the process of oxidative phosphorylation (the process of producing bulk of cellular ATP in aerobically respiring cells) ${ }^{12-17}$. The mitochondrial genome possesses unique characteristics that distinguish it from Mendelian genetic rules and it is strictly inherited through the maternal lineage. Paternally derived mtDNA is labelled with an ubiquitin, which evokes rapid targeted proteolysis when it enters the 
oocyte $^{18}$. Thus, only maternal mtDNA can be inherited. The mtDNA is polyploidy, with multiple copies of mtDNA within each mitochondrion and several hundreds, if not thousands of mitochondria per cell. Normally, all mtDNA within the cells of an individual are identical-homoplasmy ${ }^{12-17}$. However, a mutation occurring in one copy of mtDNA can eventually result in heteroplasmy (dual populations of mutant and wild-type DNA coexisting within the same cell). During mitosis, the mutant and wild-type mtDNA are randomly segregated to each of the daughter cells ${ }^{18}$. This random segregation affects both expression and inheritance of mitochondrial disease.

\section{Mendelian inheritance}

Genetic eye disorders are classified according to the type of genetic abnormality. Often the abnormality occurs on only one gene. These single-gene defects are the types of genetic abnormality called the Mendelian inheritance ${ }^{19,20}$. They are subdivided into autosomal dominant, autosomal recessive and $\mathrm{X}$-linked or sex-linked ${ }^{19,20}$. Autosomal means that the genes involved are located on the chromosomes numbered one to 22 , rather than on the $\mathrm{X}$ or $\mathrm{Y}$ sex chromosomes. To produce an autosomal dominant inheritance only one copy of the defective gene is required. The offspring of affected individuals have a $50 \%$ chance of being affected ${ }^{19}$, but the offspring of unaffected individuals are not affected. Males and females are equally likely to be affected. Most autosomal dominant traits involve structural defects.

The term "recessive" means hidden ${ }^{20}$. In other words, an individual can carry a single copy of a defective gene without showing any clinical signs. Traits of autosomal recessive tend to cause metabolic disorders, such as diabetes and hypertension ${ }^{19}$. There is a $25 \%$ theoretical risk to offspring who have two carrier parents. The characteristics of X-linked inheritance are that males are affected and females are usually unaffected carriers. There is no male-tomale transmission because the father must donate his $\mathrm{Y}$ chromosome to have a son. The risk to male offspring is $50 \%$ if the mother is a carrier ${ }^{19,20}$. (See appendix on page 188.) Unlike the Mendelian inheritance, multifactorial traits are polygenic ${ }^{20}$. There is usually a significant environmental factor in multifactorial inheritance.

\section{Some common ocular examples of genetic dis- eases}

A genetic or inherited disease is a condition that may be passed on from parent to their children through the coded information contained in the genes $^{1-6}$. Inherited disorders differ from the medical disorders in that they tend to recur within families and often, the risk of occurrence for other family members can be predicted ${ }^{1-6}$.

\section{Corneal dystrophies}

The word "dystrophy" is derived from Greek ( $d y s$ $=$ wrong or difficult, trophe $=$ nourishment). Corneal dystrophies are a group of inherited corneal diseases that are typically bilateral, symmetric, and slowly progressive and without relationship to environment or systemic factors ${ }^{21,22}$. These autosomal dominant diseases are characterized by progressive accumulation of corneal deposits beginning in the first or second decade of life. The most common inherited corneal dystrophies are the granular and lattice corneal dystrophies ${ }^{22}$. Mutations in KRT3 and KRT12 are the causes of dystrophies ${ }^{22}$. Meesmann corneal dystrophy is an autosomal dominant disorder that affects only the corneal epithelium ${ }^{23,24}$.

\section{Anterior segment dysgenesis}

Anterior segment dysgenesis (ASD) encompasses a spectrum of inherited autosomal dominant diseases that results from maldevelopment of the anterior segment of the eye $\mathrm{e}^{6,9,25}$. A serious clinical consequence is the increased risk of secondary glaucoma ${ }^{9,25}$. Mutations of PITX2 homeobox and FOXC1 forkhead genes have been found in patients with a range of anterior segment dysgenesis phenotypes ${ }^{25}$. However, mutations of these genes account for only $35 \%$ or less of cases of ASD. Therefore there are other additional genes that may play a role in this condition.

\section{Aniridia}

Aniridia is a condition where there is near-total absence of the iris ${ }^{6}$. This is an autosomal dominant inherited directly from a parent who has aniridia themselves ${ }^{25,26}$. It is the result of a mutation in a gene called PAX6 gene. Aniridia is associated with many serious ocular (eye) conditions, including cataracts, glaucoma and corneal pannus. Each child of 
a person with aniridia will have a $50 \%$ chance of inheriting the gene mutation ${ }^{20}$.

\section{Uveal melanoma}

Uveal melanoma is the most frequent primary malignant intraocular tumour in adults ${ }^{27-29}$. It arises from melanocytes located in the iris, choroid and ciliary body, which are structures of the uveal tract ${ }^{27-29}$. Cutaneous melanoma and uveal melanoma both derive from melanocytes but show distinct differences in tumour genesis, mode of metastic spread, genetic alteration and therapeutic response ${ }^{27-29}$. Not much is known about genes involved in the development and progression to metastasis in uveal melanoma compared to cutaneous melanoma ${ }^{27-29}$. This could be due to the result of the lower incidence of uveal melanoma and the small quantities of tumour sample available for research ${ }^{27-29}$. Cutaneous melanoma accounts for more than $90 \%$ of all melanomas ${ }^{30}$ whereas uveal melanoma ${ }^{31}$ is only encountered in 5\%. However, several candidate genes were proposed as causes of uveal melanoma, such as GNA11, GNAQ and DDEF1. Van Raamsdonk et $a l^{32,33}$ reported that more than $80 \%$ of uveal melanomas carry mutations in either GNA11 or GNAQ. Furthermore, the DDEF1-gene has been described in uveal melanoma ${ }^{28}$. The gene responsible for uveal melanoma is located at chromosome 8 (8q24) and found to be mutated in $50 \%$ of uveala melanomas ${ }^{34}$.

\section{Glaucoma}

Glaucoma, as a heterogeneous group of disorders, is a pathologic condition in which there is a progressive loss of retinal ganglion cells, specific visual field deficit and characteristic excavative optic nerve atrophy ${ }^{35,36}$. The major risk factor for glaucoma is abnormally elevated intraocular pressure ${ }^{35,36}$. Primary open-angle glaucoma is the most common type of glaucoma characterized by the presence of glaucomatous optic neuropathy in the absence of an identifiable secondary cause ${ }^{35,36}$. Approximately $5 \%$ of primary open-angle glaucoma has a genetic basis and is attributed to a single gene ${ }^{36}$. This is called Mendelian forms of glaucoma, that is, glaucoma caused by mutations in myocin (MYOC) or optineurin $(\mathrm{OPTN})^{36}$. These single-gene forms of glaucoma are responsible for the disease that is transmitted as a Mendelian trait often with an autosomal dominant inheritance pattern. The other mutation that may cause the development of primary open-angle glaucoma is the risk alleles ${ }^{36}$. Risk alleles do not cause disease on their own but when combined with other glaucoma risk alleles and environmental factors ${ }^{36}$.

\section{Cataract}

The transparency of the lens depends on a highly structured arrangement of lens proteins and lens fibres $^{37,38}$. About $90 \%$ of the lens proteins are crystallins $^{37}$. The crystallins are long-lived proteins located inside lens fibres, and are essential in the maintenance of transparency and refractive power ${ }^{37}$. These proteins that function in maintaining the clarity of the lens could be the potential genes causing heritable cataracts. According to Shiels and Hejtmancik ${ }^{38}$, congenital or infantile cataract can be seen within the first year of life, juvenile cataract occurs mostly within the first decade of life, presenile cataract occurs before age 45 years and senile or age-related cataract thereafter. The hereditary congenital cataracts tend to be inherited in a Mendelian fashion, while age-related cataracts tend to be multifactorial with both genes and environmental factors influencing the phenotype ${ }^{37,38}$. Hereditary cataracts are estimated to account for between $8 \%$ and $25 \%$ of congenital cataracts ${ }^{39}$. Mendelian cataracts are inherited more commonly as autosomal dominant than as autosomal recessive or X-linked traits ${ }^{38}$. A mutation in the $\alpha \beta$-crystallin gene is the possible candidate for congenital cataract ${ }^{37-39}$. This means that a mutation that severely disrupts the protein or inhibits its function might result in congenital cataracts inherited in a Mendelian fashion, while mutation that causes less severe damage to the same protein or impairs its function only mildly might contribute to age-related cataracts. Mutations in the fibrillin gene (FBN1) have been reported to be the cause of ectopia lentis ${ }^{6}$.

\section{Norrie disease}

Norrie disease is a rare $\mathrm{X}$-linked recessive neurodevelopmental disorder characterized by vitreous opacity, retinal detachment, retinal folds and fibrovascular masses ${ }^{40,41}$. The disease affects organs derived from the neuroectoderm, such as the brain, retina and inner ear. Therefore, the affected individual manifests congenital blindness, which is often associated with hearing loss, mental retardation and 
psychiatric problems ${ }^{40-42}$. Genetic linkage studies have localized the ND gene as the cause of Norrie disease ${ }^{42}$.

\section{Retinoschisis}

$\mathrm{X}$-linked retinoschisis is a relatively common juvenile retinal degenerative disease that affects males early in life ${ }^{43}$. It is characterized by mild to severe loss in central vision and splitting of inner retinal layers in the peripheral retina ${ }^{44}$. During the course of the disease, secondary complications including retinal detachment and vitreous haemorrhage can occur. Retinoschisis was first described in 1898 in two affected brothers ${ }^{44}$. Since then it has been shown to be one of the more frequent inherited retinal diseases affecting macular function in males ${ }^{43,44}$. To date 191 different mutations in the RS1 gene are known to cause X-linked retinoschisis ${ }^{44}$. The RS1 protein is expressed in the rod and cone photoreceptors.

\section{Retinitis pigmentosa}

Retinitis pigmentosa is now known as a group of clinically and genetically heterogeneous retinal degenerative hereditary diseases ${ }^{45-47}$. The disease can display X-linked, autosomal dominant and autosomal recessive inheritance patterns. Clinically, the disease is characterized by night blindness, narrowing of the visual field and pigmentary changes or alterations of the retina, eventually leading to complete loss of vision ${ }^{45-47}$. Mutations in RP1 gene seem to be the cause of autosomal dominant retinitis pigmentosa ${ }^{48}$. Mutations in the RPGR gene are the most frequent cause of $\mathrm{X}$-linked retinitis pigmentosa ${ }^{49}$. The genes more frequently involved in autosomal recessive retinitis pigmentosa are the genes encoding the subunits $\alpha$ and $\beta$ of the Cgmp Phosphodiesterase, RHO and the $c G M P$ gated ion channel protein $\mathrm{CNGC}^{50}$.

Another form of retinal dystrophy is Leber's congenital amaurosis which is an inherited condition where clinical findings commonly first appear after 2-3 months of life ${ }^{45}$. Visual function is usually poor and often accompanied by nystagmus, sluggish or near-absence pupillary responses, photophobia, high hyperopia, keratoconus and enophthalmos ${ }^{45}$. In contrast to original thinking, Leber's congenital amaurosis is now known to be caused by at least seven genes. Mutations in RPE65, RetGC1, AIPL1,
RPGR1P1, TULP1, CRB1 and CRX are known to be the cause of the condition ${ }^{45}$. Different mutations in several of these genes have been observed to cause retinitis pigmentosa and other retinal dystrophies ${ }^{45}$.

\section{Choroideremia}

Choroideremia is an X-linked, recessively inherited, progressive, diffuse degeneration of the choroid, retinal pigment epithelium and retinal photoreceptor cells ${ }^{51-54}$. It is caused by deletion or mutation of the CHM gene encoding Rab escort protein-1 (REP1). Patients with choroideremia characteristically experience nyctalopia, peripheral field loss and a characteristic fundus appearance of extensive retinal pigment epithelium and choroidal atrophy ${ }^{55}$. Virtually all mutations reported on choroideremia result in the absence of the normal protein product in affected males. Carrier females exhibit signs of patchy chorioretinal degeneration which have been ascribed to random $\mathrm{X}$-inactivation ${ }^{56}$.

\section{Albinism}

Albinism may be divided into oculocutaneous albinism affecting eyes, hair and skin; and ocular albinism affecting only the eyes ${ }^{57-59}$. Oculocutaneous albinism is a syndrome that encompasses a group of individual inborn errors, each inherited as a Mendelian autosomal recessive trait characterized by the absence or near absence of melanin pigmentation in the skin, hair and eyes ${ }^{59}$. Ocular albinism is an Xlinked trait with findings predominantly restricted to the eye. It is characterized by reduction of visual acuity, iris transillumination, nystagmus, foveal hypoplasia and hypopigmentation of the uveal tract and retinal pigment epithelium ${ }^{60}$. At present, four genes for human albinism have been mapped (OCA1, OCA2, HPS and OA1). Pathologic mutations have been identified on ACA1, OCA2 and OA1 genes. Tyrosinase (TYR) on chromosome 11q14-21 is an important enzyme in melanogenesis. Tyrosinase is categorized as OCA1 gene. Mutations in human TYR lead to the absence or decreased synthesis of melanin and thus cause oculocutaneous albinism ${ }^{60}$.

\section{Colour vision deficiencies}

Colour vision is a behavioural capacity which allows primates to discriminate variations in the spectral composition of light, irrespective of variations 
in intensity ${ }^{61,66}$. In the human eye, there are rods and cones photoreceptor cells that serve different functions. Rhodopsin and cone pigments are the lightsensitive molecules in rods and cones, respectively. Both the rhodopsin and cone pigments are collectively called photopigments or visual pigments. They are composed of a protein component called opsin and the chromophore 11-cis-retinal. Colour vision is initiated by the absorption of light quanta (photon) by visual pigments within the photoreceptors.

The human colour vision is normally trichromatic and possesses three distinct classes of retinal cone photoreceptors. The three classes of pigment differ in their relative spectral sensitivities and are commonly referred to as the blue or short-wave sensitive (S), green or middle/medium-wave sensitive (M) and red or long-wave sensitive (L) photopigments ${ }^{63-65}$. Using colour names for photopigments can be misleading. So people who are working in the field of colour vision prefer $\mathrm{S}, \mathrm{M}$ and $\mathrm{L}$ to minimize confusion.

Red-green colour vision defects are inherited as $\mathrm{X}$-linked recessive trait ${ }^{66-69}$. All red-green colour vision defects are caused by the absence of one class of cone photopigment. Tritan colour vision deficiency is a rare autosomal dominant trait and is characterized by blue-yellow colour confusion. Achromatopsia or total colour-blindness is a rare autosomal recessive trait $^{68}$. It is also referred to as rod monochromacy and it is characterized by loss of function of all cone classes, severe photophobia under daylight conditions and nystagmus ${ }^{69}$. Incomplete achromatopsia (blue cone monochromacy) is characterized by the loss of only $\mathrm{L}$ and $\mathrm{M}$ cone functions ${ }^{68}$.

The genes responsible for red-green colour vision deficiency ${ }^{66-68}$ are located on the X-chromosome at $\mathrm{xq} 28$, and the genes causing tritanopia are located on chromosome 7 (7q32). Achromatopsia is caused by mutations in CNGA3 and CNGB3 genes. To the best of our knowledge, there are no known advantages or disadvantages to having extra genes. However, the reduction of genes to less than required leads to colour vision defects.

\section{Inherited optic neuropathies}

The inherited optic neuropathies comprise a group of mitochondrial disorders in which the cause of op- tic nerve dysfunction appears to be hereditable ${ }^{69-73}$. The pathology of inherited optic neuropathies is limited to the retinal ganglion cells of the optic nerve. Optic nerve dysfunction can be the presenting and only ophthalmological manifestation causing two most common inherited optic neuropathies encountered in clinical practice - Leber's hereditary optic neuropathy and dominant optic neuropathy. The inherited optic neuropathies typically present symmetrically and bilaterally with central visual loss ${ }^{69-73}$.

Leber's hereditary optic neuropathy (LHON) is the most common mitochondrial genome disorder that presents with rapid, painless loss of central vision in one eye, followed by similar loss of vision in the fellow eye within days or months in young males ${ }^{69,70,72}$. The vast majority of cases of LHOA are due to one of three point mutation of mtDNA affecting complex I or ND genes (G11778A, G3460A and T14484C). The Leber's hereditary optic neuropathy has a non-Mendelian pattern of inheritance ${ }^{69-73}$. It is maternally inherited and all maternal offspring will inherit the mutation. This is probably because the midpiece of the sperm, which is the only part containing mitochondria, does not penetrate the ovum during fertilization ${ }^{18}$. There is evidence for small paternal contribution but to date this does not seem to have any role in disease pathogenesis. Dominant optic atrophy (DOA) is the most common autosomal hereditary optic neuropathy. Unlike Leber's hereditary optic neuropathy, it shows no sex predilection ${ }^{73}, 74$. Dominant optic atrophy typically present as slow progressive, painless, bilateral, symmetric visual loss, beginning insidiously in the first two decades of life ${ }^{73,74}$. Mutation in the OPA1 gene located at $3 \mathrm{q} 28$ has been identified as the cause of dominant optic atrophy ${ }^{73,74}$.

\section{Anophthalmia}

Anophthalmia or anophthalmos (Greek word for without eye) is a rare congenital absence of one or both eyes ${ }^{74}$. In true anophthalmia, there is a complete failure of primary optic vesicle outgrowth or the optic vesicle has degenerated ${ }^{74}$. Clinical anophthalmia is the absence of the globe in an orbit that otherwise contains normal adnexal structures ${ }^{74}$. Bilateral anophthalmia is rare. Anophthalmia is caused by a mutation in the SOX2 gene, which is responsible for the production of the SOX2protein ${ }^{75,76}$. Without SOX2 protein, the activity of genes that is important for the 
development of the eye are disrupted. SOX2 anophthalmia syndrome follows an autosomal dominant inheritance pattern.

\section{Keratoconus}

Keratoconus is a bilateral and asymmetric corneal degeneration characterized by localized corneal thinning, which leads to protrusion of the thinned cornea $^{77,78}$. It is the most common primary ecta$\mathrm{sia}^{77}$. Corneal protrusion causes high myopia and irregular astigmatism, affecting visual quality. It usually occurs in the second decade of life and affects both genders and all ethnicities ${ }^{77-80}$. The cause and possible mechanisms for the development of keratoconus remains poorly understood. However, several hypotheses have been proposed on the genetic mechanism of development ${ }^{81-84}$. Heon et al ${ }^{82}$ identified four mutations of the VSX1 gene (R166W, L159M, D144E and H244R) in different keratoconic patients. Recently, Liskova et $a l^{83}$ and Tang et al84 have shown that mutations of D144E, L159M, R166W and H244R are not related to keratoconus. The etiology of keratoconus is complicated but the genetic basis of the disease has started to be uncovered. More recently, Guan et al $l^{81}$ have shown the potential involvement of TGFB1 gene in the keratoconus of the Chinese population.

\section{Marfan syndrome}

Marfan syndrome is a disorder caused by heritable genetic defects of the connective tissue that has an autosomal dominant mode of transmission ${ }^{85,86}$. The defect itself has been isolated to the fibrillin-1 (FBN1) gene on chromosome 15 in the q21.1 locus, which encodes the connective tissue protein fibril$\operatorname{lin}^{87}$. Marfan syndrome is characterized by musculoskeletal abnormalities, cardiovascular disease and ocular abnormalities ${ }^{86}$. Most patients with the Marfan syndrome are myopic and astigmatism and have ectopia lentis (dislocated crystalline lenses) ${ }^{88}$.

\section{Stargardt's disease}

Stargardt's disease is the most common form of juvenile macular dystrophy ${ }^{89-92}$. It causes loss of central vision in adults younger than 50 years old $^{90}$. The characteristic features of Stargard's disease include progressive central visual loss, irregular yellow-white fundus flecks and atrophic macular lesions ${ }^{89,}$ 90, 92. Most patients have inherited Stargardt's disease as an autosomal recessive trait, but in some families it has been reported as an autosomal dominant trait ${ }^{92}$. Stargardt's disease ${ }^{92}$ is commonly caused by mutations of the ABCA4 gene located on the short arm of chromosome 1 .

\section{Pseudoexfoliation syndrome}

Pseudoexfoliation (PEX) syndrome is highly associated with age ${ }^{93}$. It is rarely found in patients younger than 50 years. PEX syndrome is described as a fibrillopathy that affects older patients and is marked by the production and accumulation of an abnormal amyloid fibrillar extracellular matrix ${ }^{93-96}$. The matrix is a product of abnormal basement membrane metabolism. The intraocular complications of PEX include phacodonesis and lens subluxation, angle-closure glaucoma, insufficient mydriasis, bloodaqueous barrier dysfunction, posterior synechiae and corneal endothelial decomposition ${ }^{93-96}$. PEX syndrome is currently acknowledged as the most common identifiable cause of open-angle glaucoma. Biomicroscopically, the PEX matrix will appear as white deposits at the pupillary margin and anterior lens surface ${ }^{96}$. Eyes with PEX typically respond poorly to mydriatics. The possible reason for poor mydriasis could be the development of subclinical posterior synechiae. The elevated intraocular pressure seen in PEX patients probably comes from PEX matrix blocking the trabecular meshwork ${ }^{95,96}$.

It has been shown that the PEX syndrome has a genetic factor that contributes to the pathogenesis ${ }^{93}$. PEX has been suggested to be inherited as an autosomal dominant trait. Lysyl oxidase-like 1 (LOXL1) gene has been identified as the key genetic risk factor for PEX syndrome and PEX glaucoma ${ }^{94}$. LOXL1 is an important enzyme in extracellular matrix formation $^{94}$.

\section{Discussion}

The characteristics of autosomal dominant inheritance $^{4-8}$ include the following: the affected person has an affected parent, parents can transmit the disorder to children of both sex, and males and females have the same risk of inheritance. There is $50 \%$ risk of developing the disorder to any offspring of an affected person and an unaffected mate (see Appendix on page 188, Figure 1), if the affected parent has 
one normal gene and one mutant gene. If the affected parent has two mutant genes, each offspring has a $100 \%$ chance of receiving the mutant genes and subsequently expressing the disease clinically. (A normal offspring of an affected parent whose genetic background does not demonstrate any skipped generations or mild expression of the disease can be given $100 \%$ assurance that he will have normal children.) Unaffected persons will not transmit the defective gene to their offspring unless they have an expression of the trait so mild as to be of no clinical significance. In such a case, the trait would appear to skip a generation. An example of a syndrome that falls under autosomal dominant disease is the Marfan's syndrome ${ }^{77}$.

In autosomal recessive, the affected child has clinically normal parents ${ }^{4-8}$. Both males and females children have equal risk. Transmission from an affected parent to offspring can only occur if the affected parent reproduces with a carrier for the same defects. Should such occur, $50 \%$ of the children are at risk of developing the disease and the others will be carriers. If both parents are affected, $100 \%$ of the children will be at risk. Children of an affected parent who do not marry a carrier for the same defect will not exhibit the trait but will transmit the deleterious gene to future generations. Two carrier parents (heterozygotes) for the same defect can expect 25\% of their offspring to be affected (see Figures 2 and 3 in the appendix). Stargardt's macular dystrophy is one example ${ }^{78}$.

In X-linked dominant inheritance ${ }^{4-8}$, both male and female are affected; however, females are affected more than males $(2: 1)$. When the male is the affected one, all daughters will be affected and no transmission will occur to the male offspring (see Figure 4). If the female is the affected partner, 50\% of the male and $50 \%$ of the female offspring is at risk for inheriting the defective gene ${ }^{4-8}$ (see Figure 5 on page 189).

In X-linked recessive trait, if the female is the carrier she will transmit the disease to $50 \%$ of her male offspring ${ }^{4-8}$. An affected male will not transmit the disease to his male offspring since no $\mathrm{X}$ is inherited but all of his female offspring will be carriers (figure 6). Since females have two X chromosomes, one maternal and one paternal in origin, the normal
$\mathrm{X}$ chromosome can dominate the defective $\mathrm{X}$ chromosome and therefore manifest the phenotype. The male's Y chromosome does not dominate defective $\mathrm{X}$ chromosome, and hence the complete disorder is manifested as the phenotype. One of the clinical diseases/ syndromes which fall in the X-linked recessive disorder is Lowe's (oculo-cerebro-renal) syndrome characterized by nystagmus and miotic, non-reactive pupils ${ }^{79}$. The normally white sclera may appear blue and the visual acuity may be lowered due to a cloudy cornea and/ or cataracts.

There are some defects which are due to a mutation of the chromosome itself. Syndromes which are due to chromosomal abnormalities include Edward's syndrome ${ }^{80}$ or Trisomy E, Down's syndrome ${ }^{81}$ and Wolf's syndrome ${ }^{82}$. In Edward's syndrome ${ }^{80}$ or Trisomy $\mathrm{E}$, the number 18 chromosome is found in triplicate. It affects females more than males (3:1). A mother becoming pregnant after 35 years of age is at a greater risk of giving birth to a child affected with Trisomy $\mathrm{E}$ than a younger mother. The age of the father does not appear to be a contributing factor. The child can suffer unilateral ptosis, corneal clouding and poor visual acuity due to optic nerve atrophy. Down's syndrome is due to an extra number 21 chromosome characterized by small, oblique eyelid fissures ${ }^{81}$. Nystagmus, esotropia, keratoconus and high refractive errors have also been noted ${ }^{81}$. Wolf's syndrome is caused by a deletion of genetic material from chromosome 4 and is characterized by ocular colobomas, strabismus, low birth weight and mental retardation $^{82}$. Retinoblastoma ${ }^{83}$ is due to a deletion of chromosome 13.

Another mode of hereditary transmission is the polygenic and/ or multifactorial diseases which are inherited only when a variety of genes combine with each other, with or without environmental influences to produce an anomaly ${ }^{84}$. Diabetes mellitus and hypertension are examples of systemic diseases which are multifactorial in their mode of inheritance. Patients with diabetes and hypertension also have ocular manifestations, which can lead to blindness.

\section{Conclusion}

The ocular conditions described in this review have significant visual impairment and blindness consequences. Therefore, optometrists should be 
able to diagnose the condition appropriately first before they could make any management or referral plan. An accurate diagnosis by using instruments such as slit-lamp and gonioscpy is necessary. Some of these conditions may require low vision aids to manage the visual problems before referral for genetic counseling.

\section{Acknowledgements}

I thank Kathrine Theron, a Postdoctoral Fellow in the Department of Biochemistry, Microbiology and Biotechnology, University of Limpopo for her comments and helping with the Punnet squares.

\section{References}

1. Online Mendelian Inheritance in Man, OMIM. http://www. ncbi.nlm.nih.gov/Omim.

2. Morad Y, Sutherland J, DaSilva L, Ulster A, Shik J, Gallie B Heon E, Levin AV. The ocular genetics program: multidisciplinary care of patients with ocular genetic eye disease. Can J Ophthalmol 200742 734-738.

3. McKusick VA. Inheritance in Man. A Catalogue of Human Genes and Genetic Disease. Baltimore: University Press, 1994.

4. MacDonald IM, Mah DY. Summary of heritable ocular disorders and selected systemic conditions with eye findings. Ophthalmic Genet 200021 29-49.

5. Griffin JR. Genetics review: relation to ocular disease. $O p$ tom Vis Sci 199471 164-167.

6. Young TL. Ophthalmic genetics/inherited eye disease. Curr Opin Ophthalmol 200314 296-303.

7. William MA, Carson R, Passmore P, Silvestri G, Craig D. Introduction to genetic epidemiology. Optometry 201182 83-91.

8. Burton PR, Tobin MD, Hopper JL. Key concepts in genetic epidemiology. Lancet 2005366 941-951.

9. Watson JD, Crick FHC. Molecular structure of nucleic acid: a structure for deoxyribose nucleic acid. Nature 1953171 737-738.

10. Lander ES, Lintan LM, Birren B, Nusbaum C, Zody MC, Baldwin J, Devon K. Initial sequencing and analysis of human genome. Nature 2001409 860-921.

11. Venter JC, Adams MD, Myers EW, Li PW, Murali RJ, Sutton GG. The sequence of the human genome. Science 2001 291 1304-1351.

12. McFarland R, Taylor RW, Turnbull DM. The neurology of mitochondrial DNA disease. Lancet Neurol 20021 343-351.

13. Tuppen HAL, Blakely EL, Turnbull DM, Taylor RW. Mitochondrial DNA mutations and human disease. Biochimica et Biophysica Acta 20101797 113-128.

14. Gorman GS, Taylor RW. Mitochondrial DNA abnormalities in ophthalmological disease. Saud J Ophthalmol 201125
395-404.

15. McFarland R, Taylor RW, Turnbull DM. A clinical perspective on mitochondrial disease. Lancet Neurol 20109829 840.

16. Taylor WR, Turnbull DM. Mitochondrial DNA mutations in human disease. Nat Rev Genet 20056 389-402.

17. Hatefi $Y$. The mitochondrial electron transport and oxidative phosphorylation system. Annu Rev Biochem 198554 10151069.

18. Sutovsky P, Moreno RD, Ramalho-Santos J, Dominko T, Simerly C, Schatten G. Ubiguitin tag for sperm mitochondria. Nature 1999402 371-372.

19. Sandler I, Sandler L. On the origin of Mendelian genetics. Am Zool 198626 753-768.

20. Winsor E. Mendelian genetics. Can Fam Physician 198834 859-862.

21. Warburg M, Moller HU. Dystrophy; a revised definition. $J$ Med Genet 198926 769-771.

22. Weiss JS, Moller HU, Lisch W, Kinoshita S, Aldave AJ, Belin MW, Kivela T, Busin M, Munier FL, Seitz B, Sutphin J, Bredrup C, Mannis MJ, Rapuano CJ, Van Rij G, Kim EK, Klintworth GK. The IC3D classification of the corneal dystrophies. Cornea 2008 27(Suppl.2) S1-S42.

23. MacDonald IM, Tran M, Musarella MA. Ocular genetics: current understanding. Surv Ophthalmol 200449 159-196.

24. Fine BS, Yanoff M, Pitts E, Slaughter FD. Meesmanns epithelium dystrophy of the cornea. Am J Ophthalmol 197783 633-642.

25. Churchill A, Booth A. Genetics of aniridia and anterior segment dysgenesis. Br J Ophthalmol 199680 669-673.

26. Nelson LB, Saeth GL, Nowinski TS, Margo CE, Jackson L. Aniridia; a review. Surv Ophthalmol 198428 621-642.

27. Shields CL. The hunt for the secrets of uveal melanoma. Clin Exp Ophthalmol 200836 277-280.

28. Sato T, Han F, Yamamoto A. The biology and management of uveal melanoma. Curr Oncol Report 200810 431-438.

29. Belmar-Lopez P, Mancheno-Corvo P, Saornil MA, Baril P, Vassaux G, Quintanilla M, Martin-Duque P. Uveal vs. cutaneous melanoma. Origins and causes of the differences. Clin Trans Oncol 200810 137-142.

30. Nambiar S, Mirmohammadsadegh A, Hengge UR. Cutaneous melanoma; fishing with chips. Curr Molec Med 20088 235-243.

31. Singh AD, Berman L, Seregard S. Uveal melanoma; epidemiologic aspects. Ophthalmol Clin North Am 20051875 84.

32. Van Raamsdonk CD, Bezrookove V, Green G, Bauer J, Gaugler L, O’Brien JM, Simpson EM, Barsh GS, Bastian BC. Frequent somatic mutations of GNAQ in uveal melanoma and blue naevi. Nature 2009457 599-602.

33. Van Raamsdonk CD, Griewonk KG, Crosby MB, Garrido $\mathrm{MC}$, Vemula $\mathrm{S}$, Wiesner $\mathrm{T}$, Obenauf AC. Mutations in GNA11 in uveal melanoma. N Engl J Med 20103632191 2199.

34. Ehlers JP, Harbour JW. Molecular pathobiology of uveal melanoma. Inter Ophthalmol Clin 200646 167-180.

35. Allingham RR, Liu Y, Rhee DJ. The genetics of primary open-angle glaucoma: a review. Exp Eye Res 200988 837844 
36. Fingert JH. Primary open-angle glaucoma genes. Eye 2011 25 587-595.

37. Benedek GB. Theory of transparency of the eye. Appl Opt 197110 459-473.

38. Shiels A, Hejtmancik JF. Genetic origin of cataract. Arch Ophthalmol 2007125 165-173.

39. Francois J. Genetics of cataract. Ophthalmologica 1982 184 61-71.

40. Hartzer MK, Cheng M, Liu X, Shastry BS. Localization of the Norrie disease gene in mRNA by in situ hybridization. Brain Res Bulletin 199949 355-358.

41. Ott S, Patel RJ, Appukuttan B, Wang X, Stout JT. A novel mutation in the Norrie disease gene. J AAPOS 20004125 126.

42. Chen ZY, Hendriks RW, Jobling MA, Powell JF, Breakerfield $\mathrm{XO}$, Sims KB, Craig IW. Isolation of a candidate gene for Norrie's disease. Nat Genet 19921 204-208.

43. Molday LL, Hicks D, Sauer CG, Weber BH, Molday RS. Expression of X-linked retinoschisis protein RS1 in photoreceptor and bipolar cells. Invest Ophalmol Vis Sci 2001 42 816-825.

44. Molday RS, Kellner U, Weber BHF. X-linked juvenile retinoschisis; clinical diagnosis, genetic analysis and molecular mechanisms. Prog Retin Eye Res 2012 (in press).

45. Francis PJ. Genetics of inherited retinal disease. $J$ R Soc Med 200699 189-191.

46. Testa F, Rossi S, Simonelli F. Genetics of retinitis pigmentosa. Asian J Exp Sci 200620 53-61.

47. Bird AC. X-linked retinitis pigmentosa. Br J Ophthalmol 197559 177-199.

48. Ziviello C, Simonelli F, Testa F, Anastasi M, Marzoli SB, Falsini B, Ghiglione D, Maculuso C, Manitto MP, Garre C, Ciccodicola A, Rinaldi E, Banfi S. Molecular genetics of autosomal dominant retinitis pigmentosa (AD RP): a comprehensive study of 43 Italian families. J Med Genet 200542 47e.

49. Meidl A, Dry K, Herrmann K, Manson E, Ciccodicola A, Edgar A, Carvalho MRS, Achatz H, Hellebrand H, Lennon A, Migliaccio C, Porter K, Zrenner E, Bird A, Jay M, Lorenz B, Wittwer B, Dúrso M, Meitinger T, Wright A. A gene (RPGR) with homology to the RCC1 guanine nucleotide exchange factor in mutated in X-linked retinitis pigmentosa (RP3). Nat Genet 199612 35-42.

50. Wang Q, Chen Q, Zhao K, Wang L, Trabouis EI. Update on the molecular genetics of retinitis pigmentosa. Ophthalmic Genet 200122 133-154.

51. Roberts MF, Fishman GA, Roberts DK, Heckenlively JR, Weleber RG, Anderson RJ, Grover S. Retrospective, longitudinal and cross sectional study of visual acuity impairment in choroideremia. Br J Ophthalmol 200286 658-662.

52. MacDonald IM, Russel L, Chan CC. Choroideremia; new findings from ocular pathology and review of recent literature. Surv Ophthalmol 200954 401-407.

53. Chem MS, Chang CC, Ho TC, Tsai TH, Fan IM, Hou PK. Blood-aqueous barrier function in a patient with choroideremia. J Formos Med Assoc 2010109 167-171.

54. Carr RR, Noble KG. Choroideremia. Ophthalmol 198087 169-171.
55. Krill AE. Hereditary Retinal and Choroidal Diseases. Hagerstown: Harper and Row, 1977.

56. Seabra MC, Brown MS, Slaughter CA. Purification of component A of Rab geranyl transference: possible identity with choroideremia gene product. Cell 1992701049 1057.

57. King RA, Summers CG. Albinism. Dermatol Clin 19886 217-228.

58. Ding B, Ryder OA, Wang XX, Bai SC, Zhou SQ, Zhang YP. Molecular basis of albinism in the rhesus monkey. $M u-$ tation Res 2000449 1-6.

59. Hutton SM, Spritz RA. A comprehensive genetic study of autosomal recessive ocula albinism in Caucasian patients. Invest Ophthalmol Vis Sci 200849 868-872.

60. Ray K, Chaki M, Sengupta M. Tyrosinase and ocular diseases: some novel thoughts on the molecular basis of oculocutaneous albinism type 1. Prog Retin Eye Res 200726 323-358

61. Jacobs GH, Rowe MP. Evolution of vertebrate colour vision. Clin Exp Optom 200487 206-216.

62. Jacobs GH. The distribution and nature of colour vision among the mammals. Boil Rev Camb Philos Soc 199368 413-417.

63. Rubin A. Fundamentals of colour vision awareness: a literature review. S Afr Optom 200564 102-109.

64. Vorobyev M. Ecology and evolution of primate colour vision. Clin Exp Optom 200487 230-238.

65. Deeb SS. Molecular genetics of colour vision deficiencies. Dev Ophthalmol 200337 170-187.

66. Neitz J, Neitz M. The genetics of normal and defective colour vision. Vis Res 201151 633-651.

67. Nathans J, Thomas D, Hogness DS. Molecular genetics of human colour vision: the genes encoding blue, green and red pigments. Science 1986323 193-202.

68. Nathans J, Piantanida TP, Eddy RL, Shows TB, Hogness DS. Molecular genetics of inherited variation in human colour vision. Science 1986232 203-210.

69. McFarland R, Taylor RW, Turnbull DM. The neurology of mitochondrial DNA disease. Lancet Neurol 20021343 351

70. Wai-Man PY, Griffin PG, Hudson G, Chinnery PF. Inherited mitochondrial optic neuropathies. J Med Genet 2009 46 145-158.

71. Newman NJ, Biousse V. Hereditary optic neuropathies. Eye 200418 1144-1160.

72. Wallace DG, Singh G, Lott MT, Hodge JA, Schurr TG, Lezza AM, Elsas LJD, Nikoskelainen EK. Mitochondrial DNA mutation associated with Leber's hereditary optic neuropathy. Science 1988242 1427-1430.

73. Votruba M, Thiselton D, Battacharya SS. Optic disc morphology of patients with OPA1 autosomal dominant optic atrophy. Br J Ophthalmol 200387 48-53.

74. Cohn AC, Toomes C, Hewitt AW, Kearns LS, Inglehearn $\mathrm{CF}$, Craig JE, Mackey DA. The natural history of OPA1related autosomal dominant optic atrophy. $\mathrm{Br} J$ Ophthalmol 200892 1333-1336.

75. Quarantal-Leoni FM. Congenital anophthalmia; current concepts in management. Curr Opin Ophthalmol 201122 
380-384.

76. Fantes J, Ragge NK, Lynch SA, McGill NI, Collin JRO, Howard-Peebles PN, Hayward C, Vivian AJ, Williamson $\mathrm{K}$, van Heyningen V, FitzPatrick DR. Mutations in SOX2 cause anophthalmia. Nat Genet 200333 461-463.

77. Romero-Jimenez M, Santodomingo-Rubido J, Wolffsohn JS. Keratoconus: a review. Contact Lens Anterior Eye 201033 157-166.

78. Zadnik K, Steger-May K, Fink BA, Joslin CE, Nichols JJ, Rsenstein CE. Between-eye asymmetry in keratoconus. Cornea 200221 671-679.

79. Zadnik K, Barr JT, Gordon MO, Edrington TB, CLEK Study Group. Biomicroscopic signs and disease severity in keratoconus. Cornea 199615 139-146.

80. Chopra J, Jain AK. Between eye asymmetry in keratoconus in an Indian population. Clin Exp Optom 200558 146152.

81. Guan T, Liu C, Ma Z, Ding S. The point mutation and polymorphism in keratoconus candidate gene TGFBI in Chinese population. Gene 2012503 137-139.

82. Heon E, Greenberg A, Kopp KK, Rootman D, Vicent AL, Billingsley G. VSX1: a gene for posterior polymorphous dystrophy and keratoconus. Hum Mol Genet 200211 1029-1036.

83. Liskova P, Ebenezer ND, Hysi PG, Gwilliam E, El-Ashry MF, Moodaley LC. Molecular analysis of the VSX1 gene in familiar keratoconus. Mol Vis 20074 1887-1891.

Tang YG, Picornell Y, Su X, Yang H, Rabinowitz YS.

84. Three VSX1 gene mutations, L159M, R166W and H244R, are not associated with keratoconus. Cornea 200827 189192.

85. De Backer J, Loeys B, De Paepe A. Marfan and Marfanlike syndromes. Artery Res 20093 9-16.

86. Nemet AY, Assia EI, Apple DJ, Barequet IS. Current concepts of ocular manifestations in Marfan syndrome. Surv Ophthalmol 200651 561-575.

87. Dietz HC, Pyeritz RE. Mutations in human gene for fibrillin-1 (FBN1) in the Marfan syndrome and related disorders. Hum Mol Genet 19954 1799-1809.

88. Stankovic-Babic G, Vujanovic M, Dordevic-Jocic J, Cekic S. Ocular features of Marfan syndrome. Med Biol 200815 37-40.

89. Vasireddy V, Wong P, Ayyagari R. Genetic and molecular pathology of Stargardt-like macular degeneration. Prog Retin Eye Res 201029 191-207.

90. Armstrong JD, Meyer D, Xu S, Elfervig JL. Long-term follow-up of Stargardt's disease and fundus flavimaculatus. Ophthalmol $1998 \mathbf{1 0 5}$ 448-457.

91. Haaften SCW, Boon CJF, Cremers FPM, Hoefsloot LH, den Hallander AI, Hoyng CB. Clinical and genetic characteristics of late-onset Stargardt's disease. Ophthalmol 2012 119 1199-1210.

92. Kapadia S. Stargardt's macular dystrophy. Clin Eye Vis Care 200012 71-78.

93. Schlötzer-Schrehardt U. Molecular pathology of pseudoexfoliation syndrome/glaucoma - new insights from LOXL1 gene associations. Exp Eye Res 200988 776-785.

94. Sowka J. Pseudoexfoliation syndrome and pseudoexfolia- tion glaucoma. Optometry 200475 245-250.

95. Naumann GOH, Schlötzer-Schrehardt U, Küchle M. Pseudoexfoliation syndrome for comprehensive ophthalmologist. Ophthalmol 1998105 951-968.

96. Conway RM, Schlötzer-Schrehardt U, Küchle M, Naumann GOH. Pseudoexfoliation syndrome: pathologic manifestations of relevance to intraocular surgery. Clin Exp Ophthalmol 200432 199-210.

97. Loi M. Lowe syndrome. Orphaned J Rare Dis $2006116-$ 20.

98. Hahnemann JM, Nir M, Friberg M, Engel U, Bugge M. Trisomy 10 mosaicism and maternal and uniparental disomy. Am J Med Genet 2005 138A 150-154.

99. Wong V, Ho D. Ocular abnormalities in Down syndrome: an analysis of 140 Chinese children. Pediatr Neurol 1997 16 311-314.

100. Wu-Chen WY, Christiansen SP, Berry SA, Engel WK, Fray KJ, Summers CG. Ophthalmic manifestation of Wolf-Hirschhorn syndrome. J AAPOS 20048 345-348.

101. Parulekar MV. Retinoblastoma - current treatment and future direction. Early Hum Dev 201086 619-625.

102. Awdeh ZL, Alper C. Mendelian inheritance of polygenic disease: a hypothetical basis for increasing incidence. Med Hypotheses 200564 495-498.

\section{Appendix: Probability of inheritance}

The purpose of studying genetics is in understanding how we could predict the likelihood of inheriting particular traits. One of the easiest methods of calculating the probability of inheriting a certain trait is the use of Punnet squares (named after Reginald C Punnett, who devised the approach). On the Punnet square we put the genetic contribution of one parent (father) across the top and that of the other parent (mother) down the left side.

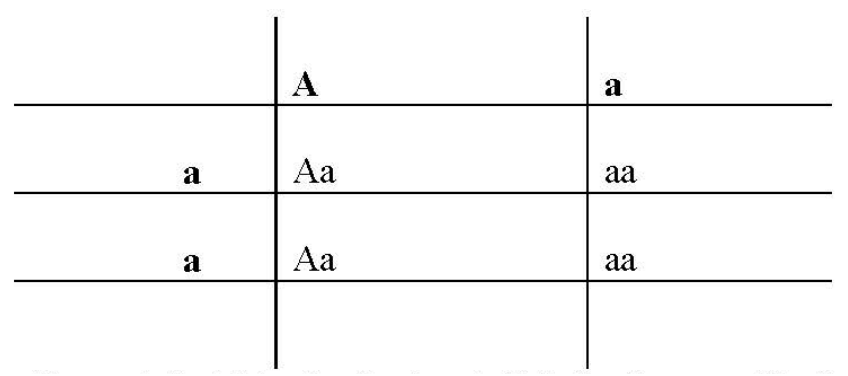

Figure 1. Let $\mathbf{A}$ be the dominant allele for the gene. If only one parent has a single copy of a dominant allele for the dominant disease, their children will have a 50\% chance of inheriting the disease and $50 \%$ of being normal. 


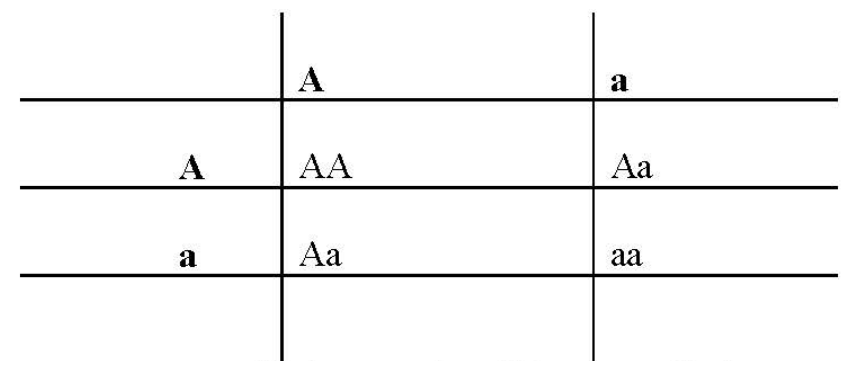

Figure 2. Let a be the recessive allele gene. If both parents are carriers of the recessive allele for the disease, all of their children will have the following odds of inheriting it: $25 \%$ chance of having the recessive disease (aa), $50 \%$ of being a healthy carrier (Aa) and $25 \%$ chance of being healthy and not have the recessive allele at all (AA).

\begin{tabular}{|c|c|c|}
\hline & A & $\mathbf{a}$ \\
\hline $\mathbf{a}$ & $\mathrm{Aa}$ & aa \\
\hline $\mathbf{a}$ & $\mathrm{Aa}$ & $\mathrm{aa}$ \\
\hline
\end{tabular}

Figure 3. Let a be the recessive allele gene. If one parent is a carrier and the other has a recessive disease, their children will have $50 \%$ chance of being a healthy carrier or $50 \%$ of having a recessive disease.

\begin{tabular}{c|l|l} 
& Xo & $\mathbf{Y}$ \\
\hline $\mathbf{X}$ & XXo & XY \\
\hline $\mathbf{X}$ & XXo & XY \\
\hline & &
\end{tabular}

Figure 4. X-linked paternal dominant: All the female (100\%) will have the mutant phenotype while no male will inherit the disease.

\begin{tabular}{l|l|l} 
& $\mathbf{X}$ & $\mathbf{Y}$ \\
\hline $\mathbf{X o}$ & $\mathrm{XoX}$ & $\mathrm{XoY}$ \\
\hline $\mathbf{X}$ & $\mathrm{XX}$ & $\mathrm{XY}$ \\
\hline & &
\end{tabular}

Figure 5. $X$-linked maternal dominant: There is $25 \%$ chance that females will not inherit the mutation, a $25 \%$ chance of having a female who inherits the mutation, a $25 \%$ chance of having an unaffected son and a $25 \%$ chance that males will be affected.

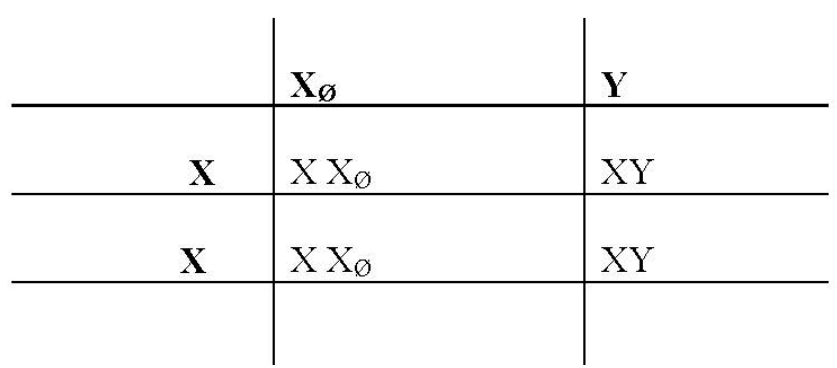

Figure 6. $X$-linked paternal recessive: There is $100 \%$ chance that all females will be carriers. 